\title{
Cultural Integration of Kazakhstan: Challenges and Opportunities
}

\author{
Sadykova Galiya, Narbekova Gulnar, and Smagulova Zaure
}

\begin{abstract}
This paper deals with the cultural integration trends in Kazakhstan and the role of nomadic culture in the current development of the country. In the environment of globalization and related to it integration process Kazakh culture as a part of the world culture is currently considered to be the distinctness of the country with its policy, socio-economic system, moral, creative and artistic heritage and potential. The paper illustrates empirical data of an opinion poll held by the authors in different regions of Kazakhstan and abroad among the locals and culture experts. The results of the research afford conclusion that the time has come to use cultural potential of Kazakhstan as a factor of modernization of the country not only in its political and economic strengthening, but also in preservation of cultural sovereignty and spiritual growth of the people as the basis for formation of cultural identity and national unity.
\end{abstract}

Index Terms-Integration, Kazakh culture, modernization, nomadism.

\section{INTRODUCTION}

Kazakhstan as a country with its ancient history and unique cultural heritage being a "bearer of almost unexplored Turkish mentality and successor to a mobile nomadic tradition, which gives a boost to its development, is building a nation at the turn of the century and millennium [1]. This spiritual and temporospatial factor connected with the characteristics of post-modern and post-industrial age, when liberal values triumph on a global basis, when not only linear development of history, but also deterministic and progressive approaches to social reality are placed in doubt, convergence of outward and inward worlds is taking place, and boundaries between the East and the West are being erased. Kazakhstan is limited neither in resources, in well-educated people, nor in many other things, "this chance can either be used or only traced just as looking after your old home turning into a speck and disappearing in the desert to the roar of an express train, travelling into the unknown" this was written by prematurely passed away philosopher $\mathrm{N}$. Sadykov, who in his reflections on the problem of civilization principles of Kazakh nation asserted that processes of integration and interaction of cultures "are related to the territorial principle of a nomad, which consists in appropriation and settlement, in possession of an absolute motion or speed" [2].

Manuscript received April 3, 2014; revised June 24, 2014.

The authors are with the Kazakh Research Institute of Culture under the Ministry of Culture of the Republic of Kazakhstan, Almaty, Republic of Kazakhstan (e-mail: ikpi.kz@mail.ru, g.narbekova@mail.ru, arclion@mail.ru).
Today, in our review of the nature of socio-cultural phenomena in Kazakh society, we may note that in the environment of contemporary globalization process, economic, political and cultural integration of Kazakhstan into the global community is growing. This process is characterized by growing competitiveness of the economy of Kazakhstan, setting-up of transnational, international companies and associations as well as interstate cultural exchange. The result of integration process can be certain modernization of political, economic and spiritual aspects of life of Kazakh society.

Modernization affecting in its turn spiritual values of the society forms a new culture in many respects, a culture based on rationalism. Some visible aspects of current trends in culture already evoke mixed views of various social strata. For example, we know about the uncontrollable processes of promoting modern primitive mass pop culture, shoddy audio-video products, non-traditional religious (sectarian) teaching and other phenomena covered in mass media, opposing to and inconsistent by nature with national traditions and spiritual values of the people of Kazakhstan. These and other fundamentally important aspects of contemporary cultural life of Kazakh society actually are still not fully understood, full-scale research was not carried yet. In this situation the chief duty of the state authorities, expert and intellectual community and cultural figures is to develop an optimal model of interaction between the state and the society, as well as to identify cultural trends, laws and principles of functioning and development of cultural experience of traditional Kazakh culture, folk art and professional art of Kazakhstan as well as private sector in culture [3]. These issues, of course, require an extensive discussion in the socio-political and expert space of the country, systematic scientific study and effective integration process management mechanisms to be developed by the government.

\section{Opportunities AND REALITIES OF CULtURAL INTEGRATION IN KAZAKHSTAN}

What is the integration level of Kazakhstan as of today? What is the reason of it and how spontaneity of this process will threaten in the longer term? How to use effectively integrative levers to put them into a meaningful activity? These and other problems are topical issues today in Kazakhstan.

Specific environment currently shaped in Kazakhstan is aimed at strengthening of economic resources and instruments utilization efficiency with highest 
productiveness. Success of the development of the country, welfare of the Kazakh community and joining global cultural process depends on the major economic indicator, which is competitiveness in the global market. Joining global cultural process envisages promotion of cultural achievements abroad, approximation of goals and objectives of the Kazakh and world culture, borrowing experience of foreign cultural institutions in addressing challenges facing national culture. Under current conditions special efforts must be made to cultivate image of the country in global mass media, including popularization of the achievements of national culture. Under these conditions, stability of the spiritual interests of a human being means existence of public interests in this field, and the government duty is to take care of the intellectual wealth of the citizens.

Today Kazakhstan is involved in the process of cultural, economic and political modernization, i.e. in large-scale process, as a result of which the society shall move from traditional or less developed social institutions to those that "are peculiar for more developed countries" alongside with basic principles of introduction of new ideas and social institutions, economic, political and social transformation to the urban and industrial society and cultural integration of society. We can clearly observe certain traits of modernization, to date the government managed to stabilize economic and financial situation, ensuring favorable economic climate for the development of productive activities and development of competitiveness determinants.

Nowadays, under the modern conditions of irreversible globalization processes there is an upward trend of economic and political integration of Kazakhstan into global community. Kazakhstan is an active initiator of many of the regional integration processes in the CIS, including organizations of Central Asian Cooperation Organization, Eurasian Economic Community, Common Economic Space and others [4]. Transnational, international, interstate companies, associations set up in recent years are intended to develop and strengthen public partnership, hold harmless from and against economic damage, if any, caused by third countries, strengthen reaction to the general economic and political threats that may arise in connection with aggravation of international competition, caused by the development of the same globalization process in the global economy.

With regard to cultural integration, we want to mention state-to-state relations in the form of a large-scale social and cultural events, tours of the on-stage performance groups and some of performing musicians through the Interstate Exchange Programs, Days of Culture of Kazakhstan Abroad and Days of Foreign Countries in Kazakhstan, joint implementation of specific programs, strengthening of cooperation in the field of culture and arts through Programs of Sister Cities, territories, regions of Kazakhstan with territorial and administrative units of foreign countries, organization of international art exhibitions, participation of artists in International Competitions and Festivals, etc. As a result of the above events people outside of our country get familiar with our arts.

As for the cultural integration of Kazakh society in general, we can say that this principle of modernization in a sense is underestimated or even ignored. Cultural integration is inevitable and practically uncontrollable sometimes even by the government. Experience of the past 1990s, when culture has been abandoned and not related to the political, economic and social structure of the country, showed how easily cultural niche can be filled with shoddy products that in a short time led to a certain "relaxedness" permissiveness and unhealthy pragmatism in the society. Moreover, integration process is not always planned or deliberately implemented by "integrating" party. The reasons of it to a large extent lie in the properties of culture itself. But culture has a unique property to penetrate and exert a decisive influence on the formation, development and functioning of all the spheres of public life. Therefore, under the conditions of dynamic globalization and related to it integration process, culture of Kazakhstan as a part of the world culture, should be regarded today as the identity of the whole country with its policy, socioeconomic system, moral, creative and artistic heritage and potential.

Freedom of choice both of economic and cultural development and attempts to build a society of prosperity will inevitably breed competition and confrontation. However, this does not necessarily mean a waiver of these attempts, and the latter should not mean to "catch up and overtake" that always ends in tears. Prospects should be linked with coming epoch and in compliance with one's own interests and interests of future generations of the country. Modern cultural integration process is manifested in adaptation of the society and its "institutional" systems to ever-changing both inward and outward conditions of its existence and is objective, therefore it becomes actual to adapt society and culture to the changes both beyond and within this situation [5]. Actualized is the problem of conformity between different elements of culture, as well as retention of internal integrity of culture of Kazakhstan, both Kazakh and Kazakhstani in general. In this connection, such problems as cultural development at the community level, connection of culture with education, transparency of cultural management, customer orientation, introduction of new technologies in culture, etc are urgent issues.

\section{THE INTEGRATION OF CULTURE OF KAZAKHSTAN IN THE WORLD CULTURAL SPACE (ON THE RESULTS OF SOCIOLOGICAL RESEARCH)}

Currently the authors are conducting sociological research within the framework of the theoretical and practical project "Vectors of Integration of Culture of Kazakhstan into the Global Space", the most important feature of which is study and investigation of directions, vectors of cultural development in line with global trends of information and cultural development. Preliminary results of the research afford conclusion that the time has come to use cultural potential of Kazakhstan as a factor of modernization of the country not only in its political and economic strengthening, but also in preservation of cultural sovereignty and spiritual growth of the people as the basis for formation of cultural identity and national unity. Kazakhs properly understand that symptoms of modern times have become globalization and integration processes, constantly expanding and having a huge impact on the existence of communities. Such situation 
of national culture do not leave it a chance to avoid global process. Perhaps that is why $70 \%$ (350 out of the total number of 500 respondents) of respondents understand cultural integration as a process of deepening of cultural interaction and mutual influence of different countries, national cultures, historical and cultural areas. And only $30 \%$ (respectively 100 and 50 respondents) of total respondents associate cultural integration with coordination process of the forms of culture and intercommunication of cultural institutions.

Under the condition of information transparency, national communities and countries actively establish political, economic and cultural coopeartion. At the same time, there is an antitotal integration tendency, which is expressed in the desire to preserve national identity, not to lose national lifestyle. Though the majority - $65 \%$ of respondents (325) answered in the affirmative to the question: What does cultural integration promote to? 65\% (325 respondents) believe that cultural integration contributes to the unity of diverse, and $8 \%$ (40 respondents) are sure that cultural integration process will lead to erosion of national identity and loss of national lifestyle:

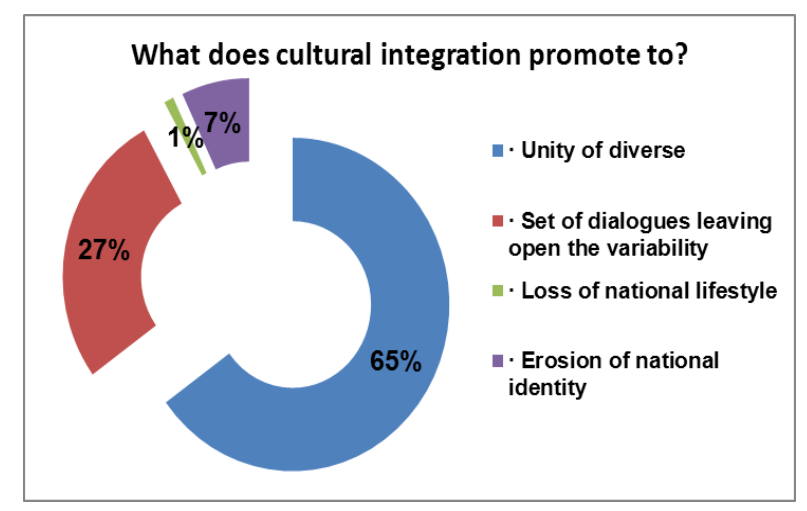

Fig. 1. What does cultural integration promote to?

Culture of Kazakhstan is open to the whole world. Kazakh culture not only expresses cultural identity of the nation, but at the same time embodies universal values of the entire global community and is a part of the global cultural heritage of human being. Foreign cultural policy is an integral part of the national policy of Kazakhstan in the international arena. Cultural diplomacy multiplies the circle of friends of Kazakhstan and makes a significant contribution to raising our foreign policy efficiency, creating conditions of the most-favored-nation treatment to develop the whole palette of state-to state relations. Preservation of cultural heritage and development of cultural potential of Kazakhstan, enhancement of its participation in international cultural cooperation, collaboration and mutual understanding - all these are reflected in the following responses of the respondents. More than half of respondents $(60 \%$ - 300) believe that art and culture of Kazakhstan may be included in the global culture through international projects, $80(16 \%)$ respondents answered in the affirmative to the question of expansion of scientific and cultural ties and 120 (24\%) respondents - to the question of exchange of innovative technologies in culture and education.

By entering into the global cultural process Kazakhstani people (250 respondents, which amounts to $50 \%$ of the respondents) mean to a greater extent promotion of achievements of national culture abroad. While to the question of approximation of goals and objectives of Kazak and world cultures and assimilation of the experience of foreign cultural institutions in addressing the challenges facing national culture almost the same number of respondents: 120 and 130, amounting to $24 \%$ and $26 \%$ respectively of the total number of survey respondents an swered in the affirmative.

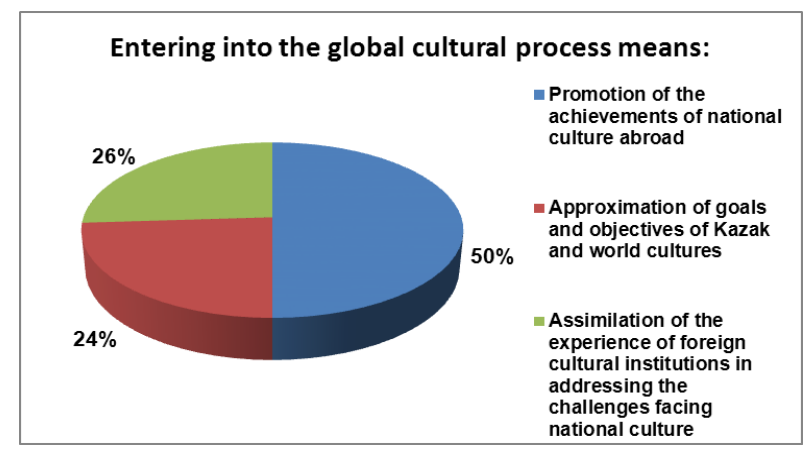

Fig. 2. Entering into the global cultural process means.

Special attention and emphasis was given to the analysis of the following question: In your opinion, what should be done to prevent total integration and unification of culture? Appeal to traditional, folk art and culture of the past in the modern context is not only the centuries-old wisdom, but also a support of ethnic identity, self-identity. It is natural that break in traditional ties leads to the loss of spiritual ancestor. Culture is always based on the traditions and shattering of the latter leads to the ruin of culture itself. Understanding of the problem from this very standpoint has made it possible for $75 \%$ of respondents to believe that to prevent total unification of culture it is necessary to support culture, which includes such factors of tradition as behavior pattern, customs, age-old values, which involve inner harmony, brain building and aesthetic beauty.

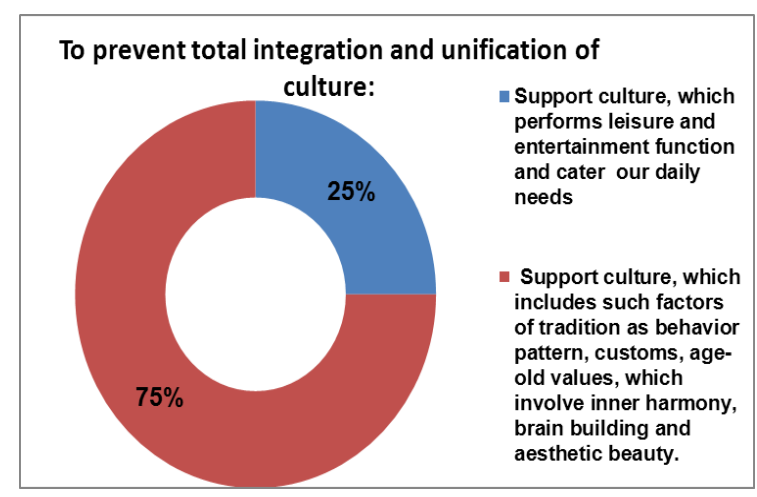

Fig. 3. To prevent total integration and unification of culture.

Current national policy of the Republic of Kazakhstan in the field of culture, as we know, is aimed at ensuring a range of measures to preserve and further develop centuries-old cultural traditions, discover new historical and cultural monuments. We know that this work has been carried out through the State Program "Cultural heritage" adopted in 2003. The Program was not limited only to restoration of 
historical and cultural heritage but had to serve as a positive shift in public conscience, heightening interest in its own history and culture, forming and strengthening national consciousness and identity and transforming cultural and historical landscape of the country.

At the moment, under the condition of globalization one of the most important areas and phases of Program implementation and cultural policy in general should be development and utilization of cultural heritage, development of technologies to identify and study cultural heritage, their key functions in the formation of modern cultural space, morphology of cultural heritage, its structure and dynamics, which will make it possible to form unifying vision of translating cultural heritage providing facilities for "revival" of cultural practice, values and patterns of the past to the benefit of the present [6].

Continuity of socio-cultural experience from the older to the younger generations must be carried out not only in the narrative form, which implies consistent and sequenced transfer of established set of samples of high level of culture but in the new paradigm that allows displacement of different cultural contexts, styles and creating new value structures based on artifacts of different levels of complexity and functionality. These processes are interpreted as pluralization of cultural value scales.

Knowledge of the past is a key to understanding of the present and the future. A person, who does not know the past, has no future. It is extremely important to hear voice of the ancestors, feel yourself being a speck of historical flow uninterrupted for millenniums. It is the link of times combined with "uniqueness and universality" that should become an "objective of culture already in the near future spiritualizing the surrounding world and enriching man's inner world" [7].

Kazakhstan in its cultural development must take into account spectacul ar examples of deadlock situation, in which quite a number of countries happened out to be, including European countries [8] and, in the future, as the successor of nomadic culture must use in full the basics of nomadic culture in its projects, without divorcing human being from nature but enrooting him in it. "The world needs a new project ... nomadism provides it with such a chance. And Kazakhstan has a unique opportunity to provide the world with a new project: Post-civilization" [2].

\section{CONCLUSION}

Any national culture is capable of self-development and reproduction as an integral formation only if the basis of such process is not only interaction of its own elements, but also its ability to interact between other cultures. Each culture in the process of its emergence and formation inevitably incorporates some elements of other cultures.

Thus, when we define significance of culture and its integration process for policy, we may highlight the following:

- First, political outlook of Kazakh society and its cultural development are interrelated and interdependent;

- Secondly, character of political system and political relationships depends not only on the balance of political forces, various other determining factors at a certain historical moment, but is also determined by historical and cultural heritage, those values, traditions, guidelines, behavior samples, psycho-emotional preferences the culture consists of;

- Thirdly, stability of political system of Kazakhstan is organically linked to preservation of multiethnic cultural diversity, which is not an isolating factor, but a source of intellectual enrichment of each human being and condition for interethnic concord and peace in civil society;

- Fourth, entering of culture of Kazakhstan into the global cultural community in the context of globalization involves the development of political guarantees to preserve its identity and urgency.

\section{REFERENCES}

[1] G. Sadykova, "Sociocultural context of the modernization of traditional culture in conditions of independence," in Philosophy in the Modern World: Development Strategies, Almaty, 2013, pp. 502-507.

[2] N. Sadykov, Kazakhstan and the World: Social and Cultural Transformation, Astana, Elorda, 2001, pp. 128-129.

[3] M. Sabit, "From idea - to ideology independence: a critical analysis," in Philosophy in the Modern World: a Development Strategy, Almaty, 2013, pp. 540-548.

[4] S. Nurmuratov, "Experience of Kazakh philosophy in shaping a new world," in Philosophy in the Modern World: a Development Strategy, Almaty, 2013, pp. 313-320.

[5] O. Stukalova. (2008). Arts integration technique. [Online]. Available: http://www.art-education.ru/AE-magazine/archive/nomer-4-2008/

[6] Z. Nazhmedenov, Konyr and Dombyra, Almaty, 2005, p. 216.

[7] S. Kolchigin, "Culture needs a new spirit," in Proceedings of the Round Table, How to Integrate Kazakh Culture into the Global Space, Almaty, Zhibek Zholy, 2011, pp. 19-23.

[8] O. Spengler, The Decline of the West, Moscow, Mysl, 1993, p. 668.

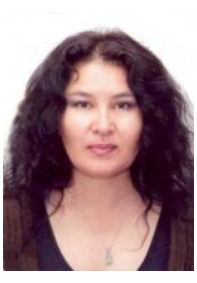

Sadykova Galiya Phd was born on October 2, 1962. She is a Ph.D. candidate, chief scientific officer at the Kazakh Research Institute of Culture under the Ministry of Culture of the Republic of Kazakhstan, Almaty, Republic of Kazakhstan.

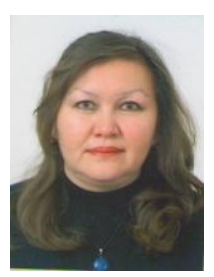

Narbekova Gulnar was born on October 3, 1962. She is an associated professor, senior research associate at the Kazakh Research Institute of Culture under the Ministry of Culture of the Republic of Kazakhstan, Almaty, Republic of Kazakhstan.

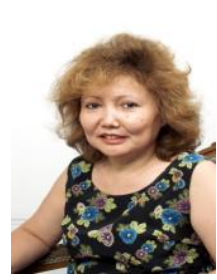

Smagulova Zaure was born on July 8, 1954. She is a scientific researcher at the Kazakh Research Institute of culture Ministry of Culture of the Republic of Kazakhstan, Almaty, Republic of Kazakhstan. 